Loading

The Journal of the Canadian Game Studies Association

LOADNG...

\title{
Dear Punchy
}

Representing and Feeling Writing in Animal Crossing

Cher Punchy

Représenter et ressentir l'écriture dans Animal Crossing

\section{Kyle Matthew Bohunicky}

Volume 13, Number 22, 2020

Animal Crossing Special Issue

URI: https://id.erudit.org/iderudit/1075262ar

DOI: https://doi.org/10.7202/1075262ar

See table of contents

Publisher(s)

Canadian Game Studies Association

ISSN

1923-2691 (digital)

Explore this journal

Cite this article

Bohunicky, K. (2020). Dear Punchy: Representing and Feeling Writing in Animal Crossing. Loading, 13(22), 39-58. https://doi.org/10.7202/1075262ar
Article abstract

This article explores how the Animal Crossing series represents and invites players to practice writing. Adopting several frameworks including media speleology, affect theory, and writing studies, this article argues that the representation of writing in the first game in the Animal Crossing series, Animal Forest, resists both the technological and gendered histories typically ascribed to writing and video games. Turning to the ways that players actually practice writing, this article suggests that affect plays a key role in the deep connections that players develop with fellow villagers through the act of letter writing. Ultimately, this article calls for further examination of writing's role in the cultural significance of Animal Crossing and careful study of its representations in other video games.
This document is protected by copyright law. Use of the services of Erudit (including reproduction) is subject to its terms and conditions, which can be viewed online.

https://apropos.erudit.org/en/users/policy-on-use/ 


\title{
Dear Punchy: Representing and Feeling Writing in Animal Crossing
}

\author{
Kyle Matthew Bohunicky \\ Assistant Professor of Digital Arts and Sciences, Digital Worlds Institute, University of Florida \\ kbohunicky@ufl.edu
}

\begin{abstract}
This article explores how the Animal Crossing series represents and invites players to practice writing. Starting with affect theory in video games, I consider how writing allows for an "incurving" of player and villager that can result in the deep emotional ties with computercontrolled characters on display in conversations across Animal Crossing fandom. Next, drawing on a media archaeological and speleological approach, I demonstrate that these expressions of affect and desire are supported by a cluster of libidinal surfaces and actions that define Animal Crossing's writing interfaces. Finally, I conclude by considering how the confluence of affect, sexuality, and gender in the writing tools and surfaces of games like Animal Crossing could potentially grant game studies access another vantage point from which to study the deep emotional bonds the emerge between players and NPCs/digital actors.
\end{abstract}

\section{Author Keywords}

Writing; History; Technology; Affect; Media Speleology; Sexuality

"Moving day has finally come." The words take me by surprise; I close the interface and grip the left shoulder button breaking into a sprint. "To be honest, I'm a little uneasy." Did I send the wrong items? Did he not appreciate the froggy chair? Why did I have to take that extended vacation? "Do you think there's a good gym in my new town?" I barrel past Phil and push aside a dosing Kiki, finally reaching the bridge. Just a little further. "What if my new rival is...better than me? Aw, man." Puffs of red and blue flower petals erupt beneath my feet. "--A determined Snake." Slowing now as I near Snake's house, my clenched finger releases the shoulder button and I drift to a stop on an empty patch of dirt. Just one week prior in the house that previously occupied this very spot, Snake would elevate my mind with weight training wisdom and lift my spirits with catchphrases I taught him from Metal Gear Solid (1998). Now, nothing remains but his letter and a dull circle of dirt. Punchy trots by, turning to watch with a vacant stare as I soak in the feelings drifting from Snake's computer-generated words. With the sun setting, I take the final remnants of my relationship with Snake and store it alongside the other letters I've received from departed villagers. Cracking open the letter writing interface and settling in for the evening, with careful taps of my stylus I begin to chisel out the contours of a new relationship, "Dear Punchy..."

Writing and written materials play a significant role in the Animal Crossing series. Since its initial launch on the Nintendo 64 as Dōbutsu no Mori (2001), players have had the ability to 
write to other players and villagers with various in-game writing interfaces. Using these interfaces, which range from a rotary phone-style input system to a simulated keyboard (depending on the entry being played), players can compose letters on digital parchment and then mail them using the game's postal service. Unlike the pre-written, binary yes/no choices that the game imposes upon players during conversations with villagers, letter writing grants players an optional and relatively open-ended means of articulating anything that the player might want to divulge. As an additional means of expression, players can attach items such as fruit or furniture to their letters, which may influence the response that players receive from the recipient. Villagers, too, tend to open up with players about anything that might be on their binary brains, and they will occasionally write players about events and observations in their life. These voluntary and freeform aspects of letter writing in the Animal Crossing series stand in contrast with the consumerist-driven goals that tend to occupy players. Here, in the empty space of the letter, players encounter a silent injunction to see the computer-controlled lumps of data dubbed "villagers" and the encounters they have had as something more than mere means to a materialistic end. Instead, the blank letter invites players to name and inscribe their feelings and perceptions, protruding through the written word a discursive bond between player and machine that gives the villagers what Roland Barthes might describe as their "punctum": the way by which a villager (like Snake) comes to singularly grip us.

The emotions and affective sensations that connect players and computer-controlled villagers via written materials and letter writing has been a topic of interest for many game scholars working with titles in the Animal Crossing series. Emily Flynn-Jones (2014), in "Game Cutification: A Violent History of Gender, Play and Cute Aesthetics," describes the significance of player-produced paratextual writing and how cuteness is inscribed through various communication practices. In the Animal Crossing community, writing accompanies interactions like "cute gifting," and it documents players' affection for (and protection of) certain characters. Shifting from players to designers, in "The Rhetoric of Video Games," Ian Bogost (2008) explains how the series provides a strong example of procedural "authorship," which describes how game designers use processes to write expressions into and through the broader operations of in-game systems that players participate in during play. Finally, John Murphy and Jose Zagal (2011), in "Videogames and the Ethics of Care," situate the in-game practice of letter writing as a means by which players deepen their ties to villagers and in turn shape their treatment of these non-playable characters (NPCs).

Although it might seem strange for writing to crop up in much of the critical work on the Animal Crossing series, continued interest in the question of writing in various Animal Crossing titles and its connection to players' emotional investment within the series is somewhat explained by series designer Katsuya Eguchi's (2008) comments on the series' inspiration. In an interview with Edge Magazine, Eguchi explains how practices maintaining emotional connections while at a distance from friends and loved ones served as a key motivation for Animal Crossing:

Animal Crossing features three themes: family, friendship and community. But the reason I wanted to investigate them was a result of being so lonely when I arrived in Kyoto! Chiba is east of Tokyo and quite a distance from Kyoto, and when I moved there I left my family and friends behind. In doing so, I realised [sic] that being close to 
them - being able to spend time with them, talk to them, play with them - was such a great, important thing. I wondered for a long time if there would be a way to recreate that feeling, and that was the impetus behind the original Animal Crossing. Eguchi (2008)

True to Eguchi's experience, the Animal Crossing series effortlessly simulates the troubles of separation that stem from various forms of labor (running errands, maintaining employment, etc. within and outside of the game), and writings (be it through letters, emails, text messages, etc.) serve as one means of remotely sustaining emotional ties. Despite the cheerful faces that populate players' towns, losing touch with and becoming distant from villagers because of the multitude of daily tasks both within and outside of the game that distract players is a common experience in the series. This experience is exacerbated by the in-game clock that keeps villagers living their lives, interacting with other players/villagers, and even leaving town whether or not the player is playing the game. Thus, while mainline Animal Crossing titles are marketed and often praised for the connections that players can share with villagers, a significant portion of the game is in fact spent separate from them. But for this very reason, even though writing is never imposed upon players, many players end up experimenting with writing because it provides a convenient way to check in and care for villagers, even if players should happen to miss them during their endless erranding.

With writing positioned as a core aspect of the series and its scholarship, I offer here two intertwined avenues for reading the significance of writing in various Animal Crossing titles. Starting with affect theory in video games, I consider how writing allows for an "incurving" of player and villager that can result in the deep emotional ties with computer-controlled characters on display in conversations across Animal Crossing fandom. Previous critical discussions of writing in the Animal Crossing series have expounded upon the human side of this practice, particularly investigating writing to other players within and around the games. To this conversation, I add the nonhuman writer/recipient by suggesting that we might further investigate the bonds created and sustained with computer-controlled, non-playable characters (NPCs) through letter writing. This practice of "sensing along surfaces" leads into a study of the specific kinds of surfaces that players use to incurve with NPCs. To understand these surfaces, I draw on a media archaeological and speleological approach to demonstrate how these expressions of affect and desire are supported by a cluster of libidinal surfaces and actions that define Animal Crossing's writing interfaces. Specifically, I discuss how Dōbutsu no Mori, the first title in the series, swapped the prominently phallic erotics of both writing technology and the Nintendo 64's joystick with a gender- and sexually-fluid surface for inscribing player desire and feeling. Finally, I conclude by considering how the confluence of affect, sexuality, and gender in the writing tools and surfaces of games like Animal Crossing could potentially grant game studies access to another vantage point from which to study the deep emotional bonds that emerge between players and NPCs/digital actors. Through such work, I seek to both contribute to ongoing studies of the cultural cache that Animal Crossing has within player communities and also gesture towards the value of continuing to investigate how and what we write to humans and nonhumans alike within video games. 
4 Loading... The Journal of the Canadian Game Studies Association

Vol 13(22): 39-58

http://loading.gamestudies.ca

\section{Affective Crossings and Emotional Compositions}

In this section, I frame writing to and with NPCs in Animal Crossing as an activity of "sensing along surfaces" using affect theory and phenomenological studies of video games. Through my exploration of these frameworks, I suggest that they might present a way of understanding how the writing surfaces within Animal Crossing can create significant emotional ties that players cite as critical to their experience with the series. Writing to villagers and the written remains players receive from them are often described as having a kind of grip on players (seen both in the surrounding discourse and preservation practices). This grip arises from the multiple ways in which player, machine, and animal undergo an affective "incurve" at the level of the written word that leaves behind an emotional remainder bonding player to villager in a human-animal-machine hybrid.

Letter writing's significance within the Animal Crossing series comes, in large part, from the appeal of the series' cast of nearly 472 friendly, roving, non-playable villagers also hopping from village to village in the hopes of finding a place to call home. Rather than centering its narrative, gameplay, and merchandise on a single player-controlled character, many of Animal Crossing's non-playable villagers share as significant (if not more so) a role as the player character.

Villagers within Animal Crossing are humanoid animals programmed to follow their own routines and set schedules within the town, occasionally crossing paths with the player during an errand or accosting them mid-task. Such acknowledgements are not unwelcome, however, as Animal Crossing's real-time clock system, which tracks the passage of time even when the system is turned off, means that much of the game occurs without the player. Villagers will leave, seasons will change, and events will occur regardless of the player's presence in the game. Thus, these "check-ins" with the player serve to procedurally ensure that the player feels acknowledged and important to the town despite the game's larger ambivalence towards player presence.

This balance between real-time independence and occasional attentiveness stimulates a sense that villagers have their own "lives" (Murphy \& Zagal, 2011, p. 75), which surprisingly prompts a heightened degree of care and emotional connection from players. In "Videogames and the Ethics of Care," Murphy and Zagal theorize that the villagers" "illusion of independent action, or liveliness" lends to players' perception of them as equals with "wills of their own," and this equality helps to increase emotional attachment which in turn motivates players' desire to maintain relationships with these NPCs (Murphy \& Zagal, 2011, p. 75). Letter writing, they suggest, deepens these attachments because it "requires an investment of time in building a relationship...The act of thinking of what to write in a letter is also a form of selfexpression that personalizes the experience for the player" (Murphy \& Zagal, 2011, p. 76). Players can, in many ways, let other characters know what they think and feel about them and the town. In perhaps one of the most famous examples, players can equip a bug net and use it to repeatedly strike a villager to push the villager into a state of sadness or frustration. While play-based examples of authoring one's feelings through actions do exist, letter writing is a bit different from these examples due to the depth and breadth of communication and the cultural narratives of intimacy that surround this genre. Whereas bug netting is an open and observable act performed publicly, the letter is private and concealed, and this distinction contributes to 
the letter as a confessional and personal experience.

To write a letter, players must first acquire an item called "stationary," either through trade with other villagers/players or through purchase at Tom Nook's (or the Nooklings' in later iterations) shop. Stationary is a permanent item category in the Nook shops, which means that players are always guaranteed to have access to letter writing each day. In Animal Crossing: New Leaf, stationary appears in 65 different styles, allowing players to choose an accompanying design in the body and margin of the letter that reflects their mood or message. Once stationary has been moved into a player's inventory, messages of approximately 162 characters can be composed using the game's writing interface. Upon selecting the letter in their inventory, players are first prompted with a menu of possible recipients for their letter before the message can begin, thereby directing the content of the message with the addressee. Once players have finished writing a letter, it automatically transforms from stationary into a letter item that they can then mail to villagers or other players.

Letters are mailed through the in-game Post Office and, once mailed, are read against a seven point scoring system that determines how the recipient responds and "if your letter is good enough...with a special present attached" (Radulovic, 2018). In "The Animal Crossing Letter System, Explained," Radulovic describes how this system determines the response based on a score it derives primarily on the letter's grammar rather than its content. The first set of points are determined by checking whether the player ends their letter on a period and if letters are capitalized no less than three spaces after a period. Next, a score is awarded for using trigrams, then the player earns additional points if the first letter of the letter is capitalized. The player can lose points at the next check if they have repeated the same letter three times in a row or more. The following check looks for the ratio of spaces to letters, awarding points for letters that have an even balance of letters and spaces. The last two checks look to deduct points if the player has written more than 75 characters with no punctuation and whether a space occurs every 32 characters. This system's focus on superficial elements such as punctuation and spacing can result in compositions that, to a human reader, would be inscrutable but that "make sense" to Animal Crossing's machine reader. A letter, for example, containing a series of individually capitalized letters separated by periods will receive a high score of 850 points, whereas one describing the village might struggle to receive such marks (Radulovic, 2018). For players looking to optimize their item acquisition, letter writing presents an easy means of ensuring a daily shipment of stuff to customize their homes and villages.

Given some of the narrowly materialist and brutally efficient play styles on display in Animal Crossing's player communities (Bogost 2008), we might assume that players' letters only consist of illegible messages written strictly for the highest amount of points. Yet while players do use letters as a means to acquire furniture and complete tasks within the game (a practice literalized by Cuyler's (2018) "Letter2Item" mod that automatically adds an item to the player's inventory just by writing a specific code in the body of a letter), there exists an equal number of players in the Animal Crossing community who recount writing letters for less self-serving purposes. Natalie Flores' (2019) "Why Do Animal Crossing's Villagers Leave Such an Impact?" for example, reminiscences on the significance of her emotional connection to a villager named Oliver, noting that "I'd write a letter to her almost every day" on a range of topics from isolation at her school to the meaning of her relationship this 
villager. Similarly, Nommeh (2014), a poster on the Animal Crossing subreddit, asks "what kinds of things do you write in your letters to villagers?" In their post and the responses that follow, players describe letters as an important site for both bonding and expressing their emotional attachments to the villagers that populate their towns:

I also can't resist sending a "welcome" letter to anyone who moves in...I must be sad but I don't ever want a villager to show anyone a blank letter as one of the ones they "treasured" and I've sometimes had a good laugh at the dumb stuff I wrote when villagers showed me months later. (Nommeh, 2014)

Responses to Nommeh's post cover a wide range of emotions that include trying to help villagers tidy up their homes by sending them furniture (Evermore-Apples, 2014), asking them about their wellness and happiness (erinhasguts, 2014), or using them to confess their inner feelings about the town and life (thevdude, 2014). Perhaps most interesting, however, is the general sentiment that despite the villagers' existence as data that reads and responds to letters according to a rigid procedure, players put thought and effort into their composition, "though sometimes I feel silly for doing that since they wouldnt [sic] be able to tell the difference between a bunch of random words or meaningful letter." Players' letters, like many of those documented in YouTube videos and on social media sites/forums, expresses concern for their relationship with chunks of data represented as a character often through self-reflective questions over how a letter might make a villager feel, and what sort of future relationship it might result in for both player and villager.

To better explain players' concern with machine feelings and anthropomorphized data, I turn to Aubrey Anable's (2018) presentation of affect in Playing with Feelings. In her text, Anable presents affect as a current running along the surface of the body that bridges what she calls the discursive body (that aspect of the body enmeshed in signifiers of race, gender, class, sexuality, etc.) and the sensory or corporeal body (the meat, flesh, and autonomic systems) (Anable, 2018, p. 67). In Anable's model of affect, the corporeal body galvanizes in response to some stimulation, but this galvanization is always encased within the discourse of the body and its histories. Her presentation of affect as a link between discourse and corporality differs from the standard presentation of affect within Deleuzoguattarian theory and as it has been taken up by scholars like Brian Massumi (2002). In these works, affect does not link discourse and corporality, but rather it separates the two and exists independently of discourse. As Anable explains, "affect theory attuned not to subjects and representations but rather to presymbolic 'intensities' has left us vacillating between sites of meaning somehow outside or underneath the symbolic and subjective" in an attempt at disposing of the cultural politics of the body (Anable, 2018, p. 67).

Instead of countering with the Derridean argument that all is discourse, Anable proposes that we "start in the middle" by viewing affect as that which holds the discursive and sensing body together (Anable, 2018, p. 36, p. 9). This middle, denoted through the surface, is generated in the crossing of discourse and corporality and is marked by the "embodied capacity to feel" as we "touch the game and the game touches us" and experience what Anable classifies as a "pulling in and down" towards the game via its surfaces (Anable, 2018, p. 67). Brendan Keogh (2018) addresses this moment of touching and being touched through his concept of video 
games as "partial worlds" that are dependent upon and constructed through players' voluntary distribution of their senses across their bodies and onto the images adorning their screens as a textual strategy for "completing" the game (Keogh, 2018, p. 55). Neither here nor there, the player and game exist in the interstitials or what Souvik Mukherjee (2015) describes as an "incurving" of the player and game during which "the player is the gun in one sense while in the sense supported by the game logic, she has the gun" (Mukherjee, 2015, p. 162-163). Incurving involves an inseparable crossing from game to perception to action back to game; it marks the moments that player senses spike their embodiment across a flesh-hardware-image relay in a strange sensation of both "here" and "elsewhere-ness." For example, a visualprocedural event such as a cacodemon turning towards me (my player character) is recognized and, at almost the same time, a motor event in my left finger contacts the controller trigger and fires off plasma in a (seemingly) fluid movement during which time I feel myself both in Gainesville and in DOOM's Phobos Base. Between this perception and resultant action, in this middle between flesh and gamic discourse, is where Mukherjee similarly locates "affect," or "the region of the possible and the zone of passing from one quality to another or the development of the expression of a power," where player senses cross into gamic actions and, briefly, affectively tether player and game (Mukherjee, 2015, p. 167). As Anable observes, affect holds us tightly up against our games and creates the sense that we touch and are touched in turn.

In terms of Animal Crossing, writing provides a crucial surface along which players sense that they might touch and be touched by the villagers populating their town. Anable explains that, "I use the term affect...to refer to the aspects of emotions, feelings, and bodily engagement that circulate through people and things but are often registered only at the interface - at the moment of transmission or contact — when affect gets called up into representation" (Anable, 2018, p. xviii-xix). In Animal Crossing, the word and letter represent this very surface along which affect travels and brings the player's sensing and discursive body together with the villagers within the game, creating a crossing that bridges the surface of skin and screen. For much of the game, players are acted upon by the villagers and townsfolk, pressing the A button to progress through line after line of computer-generated text that represents conversation with villagers. Outside of the occasional binary yes/no decision and opportunity to run an errand for a villager, players are decidedly less expressive during conversations than the villagers. Writing, however, puts players in the position of the villager, now able to summon text-based expressions of their experiences within the town and beyond. Particularly, the blankness of the writing interface thrusts a surface before the player that brings together discourse (in the form of written words) and all the silent corporeal experiences that players have undergone through their time as a resident of Animal Crossing.

In this way, then, we can see the writing surface as the skin on which players galvanize their feelings into discourse, but it is also important to acknowledge that this moment is also one that is addressed to a computer-controlled character. The affective experience of composing a letter is not just an opportunity to shout into the void, but rather a re-direction of feeling towards the cluster of data and art assets that I've been referring to as "villagers." As Anable reminds us, in touching video games there is always a moment of being touched, and when writing in Animal Crossing the player in turn simulates an experience of what this villager 
8 Loading... The Journal of the Canadian Game Studies Association

Vol 13(22): 39-58

http://loading.gamestudies.ca

might think and say about their expression - in other words, they feel what Keogh describes as a "consensual hallucination" of a villager's thoughts and feelings towards them. This experience gives villagers an important quality of "presence" that exceeds many of the purely procedural readings that tend to define villagers' "realness" for players in terms of an algorithm that has villagers perform actions even when the player is away from the game. Villagers exist because we feel their existence, and this quality of feeling is key to writing's significance within the series from both a speleological and fan-based perspective.

\section{Writing Archaeology in Animal Crossing}

Vital to this junction between player and villager are the devices with which players inscribe the page. These devices, both the controller and its representation within the game as a visual interface, structure the feelings players convey and receive within the Animal Crossing series. In this section, I shift my focus from player and villager to the specific tools that facilitate their affective exchanges. The design of these tools presents what Laine Nooney (2013) describes as "media speleology," a method that stands in contrast to reconstructive practices like media archaeology that fit discoveries into a preconceived "skeleton" of larger historic events and inventions. Instead media speleology, as a method for doing game history and reading various aspects of video games, "is a phenomenologically imprecise encounter" that "relies on non-continuity and the inability to apprehend the historical field in its wholeness" in a rejection of chronological envisionings of technology and history.

In "A Pedestal, A Table, A Love Letter: Archaeologies of Gender in Videogame History," Nooney positions speleology as a practice of feeling history's surfaces. Speleology grasps at limits, and Nooney defines the practice in contrast to other approaches at video game history:

I don't want to get out my shovel and "penetrate beyond" historical "surfaces"...I'll settle for something that "gropes toward its limits"...Media "archaeology" implies an excavation that brings objects into the light of knowledge, constructing a larger skeleton from the wreckage of bones scattered across the historical field. Spelunking, in contrast, is a phenomenologically imprecise encounter -- I can only see so much at any one time. The shape I hollow out here relies on non-continuity and the inability to apprehend the historical field in its wholeness. (Nooney, 2013)

While speleology, a term Nooney derives from cave spelunking and depth, could be read as at odds with Anable's focus on surfaces, Nooney's summary frames spelunking as a practice of imperfectly surfacing a cave system (or field) by touching and sensing its contours and caverns through feeling. As Anable notes, "Spelunking, for Nooney, is not about digging to reveal an obscured history but rather about groping in the dark to sense the embodied and structural limits of what media histories and analyses can reveal" (Anable, 2018, p. 3).

Before applying media speleology to the Animal Crossing series, it's important to note that this is not an argument about the developers' intentions behind the incorporation of writing technology in the Animal Crossing series; instead, media speleology presents a method for 
sensing (via touch) the histories and representations of technology video games. To bring media speleology into conversation with writing in the Animal Crossing series, I focus on how we touch its writing tools and how surfaces invoke anachronisms within its representations. This approach is especially fruitful when examining how the Animal Crossing series pairs its sense of writing technologies with the various controllers that have accompanied each new game in the series. This anachronistic pairing of what might be read as "traditional" forms of feeling and using symbolic communication (in other words, writing letters and text) with more "recent" forms (such as gestural inputs with a joystick or touch pad), results in a blending of what Christina Haas (1996), in Writing Technology: Studies on the Materiality of Literacy, describes as "historicizing technology" with Lisa Gitelman's (1999) call in Scripts, Grooves, and Writing Machines to resist deterministic accounts of technology (Haas p. 205, Gitelman p. 2). The pairing of "old" and "new" technological senses and feelings within in a temporal setting that is somehow simultaneously both pastoral and industrialized (see, for instance, the contrast of Animal Crossing: City Folk's (2008) looming modern city) makes such innovations seem less like teleological inevitabilities and, perhaps most strangely, results in an emptying of what might be envisioned as "essential" to writing and digital controllers - those functions, rhetorics, and histories that are identified as the essence of a technology. In doing so, the Animal Crossing series is able to feel out the intersections between the contemporary and the historic, resulting in hybridized devices that reveal both the non-linear history of digital technology as well as how these devices shape and are shaped by broader cultural narratives about communication, society, embodiment, etc. In this way, then, the technology in the Animal Crossing series performs a radical re-writing of writing and technological history that generates possibilities rather than historic closures.

Given the many releases and accompanying revisions of writing throughout Animal Crossing's long history, I focus my analysis here on the perhaps lesser known example of Animal Forest's "dial input system." Whereas most video games lacking keyboard integration include a virtual keyboard that can be used to type out responses by selecting a letter, number, or symbol on a graphic interface resembling an actual keyboard, the dial input system allows players to write names, responses, and messages by selecting letters, numbers, and symbols from a ring using the Nintendo 64's joystick. The dial input is, in short, not an adaption of a pre-existing metaphor for writing, but rather a completely new metaphor arising from the convergence of writing with the Nintendo 64's controller. Perhaps unsurprising, then, is the resemblance between Animal Forest's writing interface and the Nintendo 64 controller (Figure 1.1) with the notable exception being of course the dial input system which appears as an alphanumeric ring encircling the joystick. 


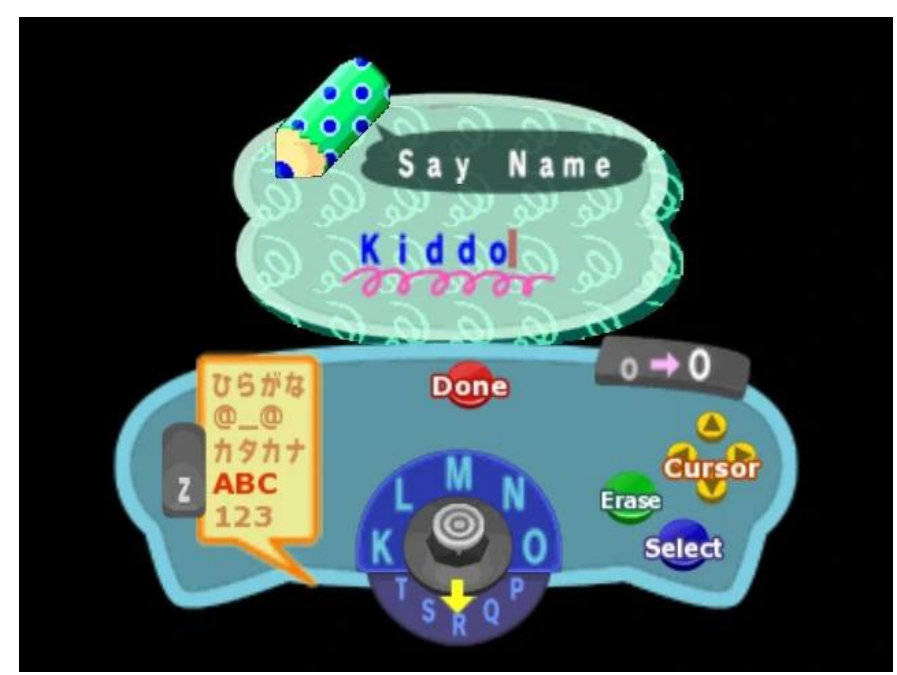

Figure 1.1. Dial Input Writing System in Animal Forest

In addition to this ring, the controller buttons are represented in the location that they appear on the player's controller with labels to indicate how they may be used to write and edit text (excluding the $\mathrm{L}$ trigger and directional pad). On the input dial itself, a set of five letters and symbols are mapped to the joystick's horizontal, upper-diagonal, and upper-most inputs, allowing the player to enter a letter or symbol by circling the joystick in the direction that it is assigned and pressing the A button for "Select." Pressing down on the joystick allows the player to access a different set of five letters and symbols, and players can scroll through series after series of five letter/symbol chains this way. The camera buttons serve as arrow keys for moving the cursor between letters, and B and A buttons allow players to Erase and Select letters respectively.

What we feel here are several technological grammars fused together as a result of integrating current technology (the controller) into a game that thematically resists the pressures and presence of such technologies. A brief review of marketing materials for the Nintendo 64 reveals that the feeling and senses introduced through the controller's joystick was a central selling point for the console and one of the key ways that Nintendo's first attempt at a console focused on 3D spaces and polygons would distinguish itself from the already 3D PC market (Figures 1.2 and 1.3). 
11 Loading... The Journal of the Canadian Game Studies Association

Vol 13(22): 39-58

http://loading.gamestudies.ca

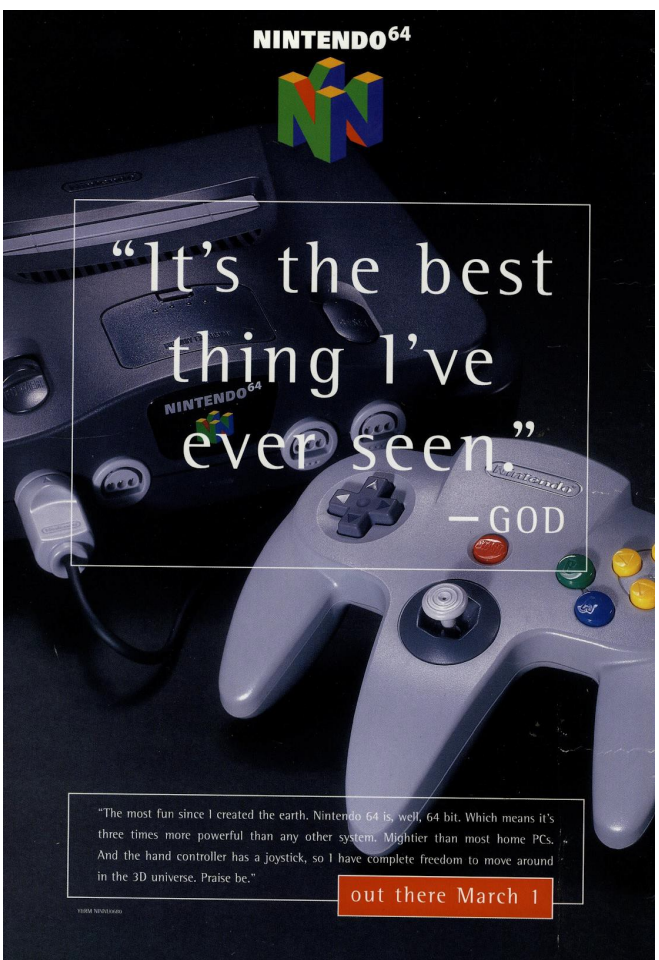

Figure 1.2. Nintendo 64's 3D joystick, sight, and feeling "complete freedom"

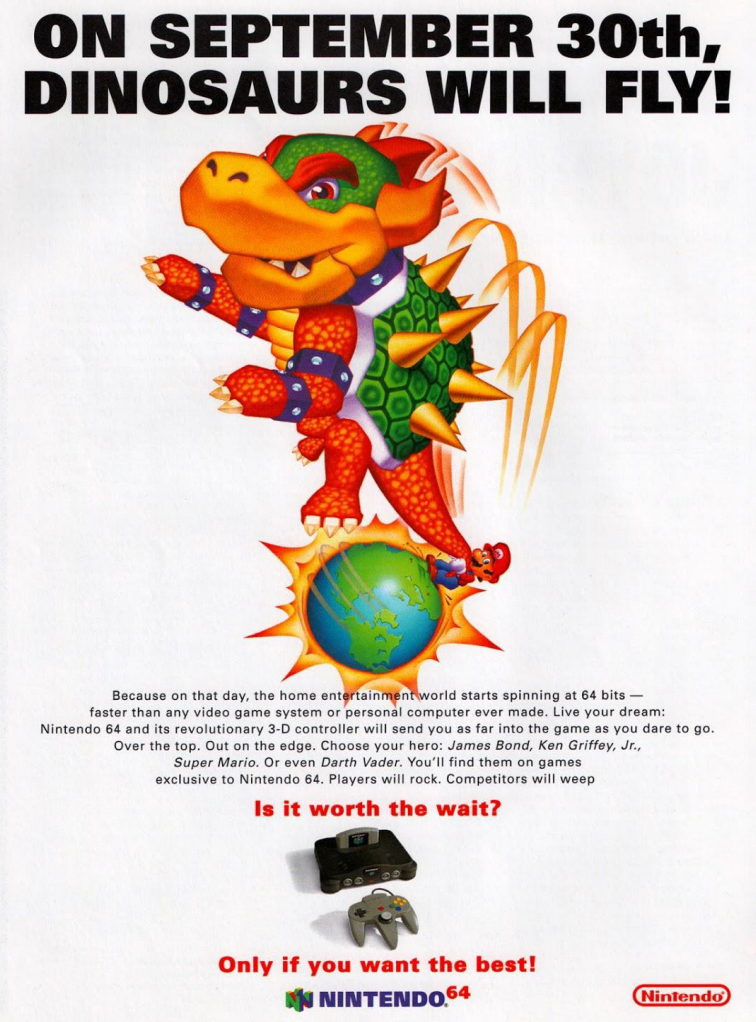

Figure 1.3. 3D controller, visualizing the sense of rotation and revolution in 3D space, and feeling at freedom 
12 Loading... The Journal of the Canadian Game Studies Association

Vol 13(22): 39-58

http://loading.gamestudies.ca

Perhaps as a result of this competition between console and PC, the developers of Animal Forest were compelled to remove references to the computer such as a virtual keyboard, or perhaps this unique writing system was a result of an overzealous push to foreground the sensations provided by the $3 \mathrm{D}$ joystick in as many scenarios as possible. Whatever the case, the input dial displaces keyboard keys as writing's "logical" evolution from pen and paper and instead explores what writing system might have emerged if, instead, the joystick took their place. 
In blending writing and joystick, a secondary writing (in this case, a re-writing) occurs that senses alternative histories and futures for both. Many cultures write along a horizontal or vertical axis, thereby affixing to writing the quality of linearity and progression. One feels that they are always writing towards something, and the computer keyboard materializes this axisdriven perspective on writing by aligning letters and symbols on a grid. In Does Writing Have a Future? Vilèm Flusser (2011) identifies this grid-based linearity as writing's defining feature: "Writing, in the sense of placing letters and other marks one after another" (Flusser, 2011, p. 3), and he gestures towards how the linearity of writing systems and technology have in fact deeply shaped our perspectives of time and causality. From these perspectives, the dial input system presents a radical break from not just what writing means, but how it organizes our very notions of history and temporality. Although players do organize letters in linear patterns after selecting them, the dial with which they select these letters does not adhere to a strictly X Y axis, thereby exploring how writing's so-called essential qualities are not so central as we might suppose, and inventing a new temporal and spatial relationship with writing.

Building from these observations, the dial shares a partially similar feeling as rotary phones, merging inscription (representation) and speech (reproduction) technologies at the site of the player's joystick. If we follow the notion that these anachronistic encounters create ruptures in our identification of what writing is and is not, then this synthesis results in a significant reconceptualization of writing. The joystick is a navigational device for players to move, select, aim, choose, etc. in a variety of different 2D and 3D spaces. In its synthesis with writing, we might begin to glean connections between the spatial sensation and writing, particularly that our movements can be (and often are) symbolized and represented back to us within video games. This conceptualization of writing is literalized in Animal Crossing: City Folk, which features grass that will wear down and show tracks based on where the player tends to walk--effectively allowing players to write their play onto the environment. The dial input system, in diluting the boundaries between actions like writing and navigation through feeling, allows us room to consider whether actions that we might not normally classify as writing could, indeed, be writing.

Perhaps most critically, especially when working from the perspective of media speleology, is the understated but implicit gendering of writing that converges through this technological pairing. More than just a framework for envisioning the chronology of technology, media speleology seeks to "critically inquire into the ways gender is an infrastructure that profoundly affects who has access to what kinds of historical possibilities at a specific moment in time and space" to locate the ways in which certain bodies are privileged over others (Nooney 2013). Looking at the popular rhetoric in advertisements for both the Nintendo 64 and other consoles, it becomes quickly apparent that the feeling of the joystick was framed as a metaphor for playing with a phallus (Figure 1.4 and Figure 1.5).

Both Brenda Brathwaite (2006) and Amanda Phillips (2017) have documented the sexual metaphors of hardware that are actualized through what Phillips calls "sexual analogues, in which controller functions mimic sexual activity" (Phillips, 2017, p. 117). Reading Bayonetta's analogues in joystick motions and button presses, Phillips describes how the feeling of and actual performances with a joystick maps the scopic pleasures of striptease 
14 Loading... The Journal of the Canadian Game Studies Association

Vol 13(22): 39-58

http://loading.gamestudies.ca

with "dealing damage to the unfortunate audience of this spectacle" (Phillips, 2017, p. 117) whereas rapid button presses during Climax finishers "invoke clitoral masturbation" (Phillips, 2017, p. 118). Given the prominence of advertising appealing to and inscribing the perspectives of cisgendered men (Shaw, 2014; Mills, 2015), it is possible to read the joystick alongside the trope of pen and pencil as emblematic of enacting cisgendered male sexuality (King, 1995). 


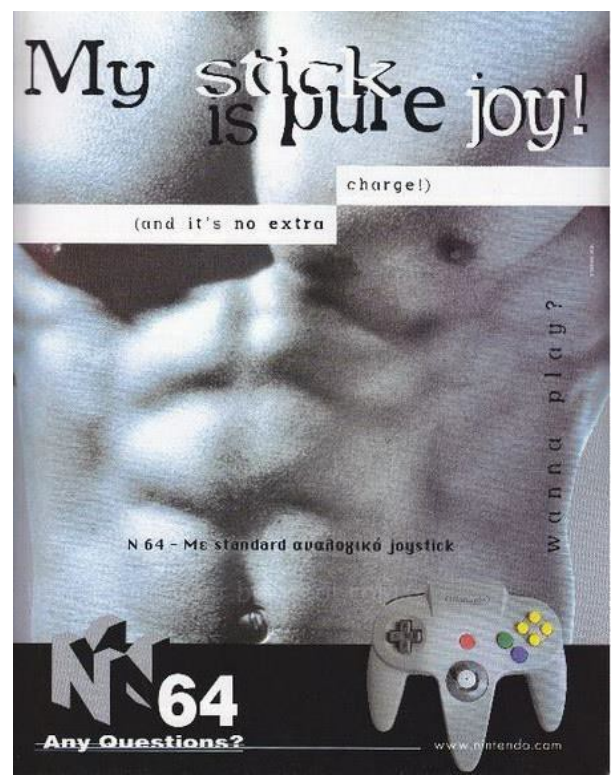

Figure 1.4. Mapping masculinity, pleasure, play, and the phallus to the Nintendo 64 Joystick

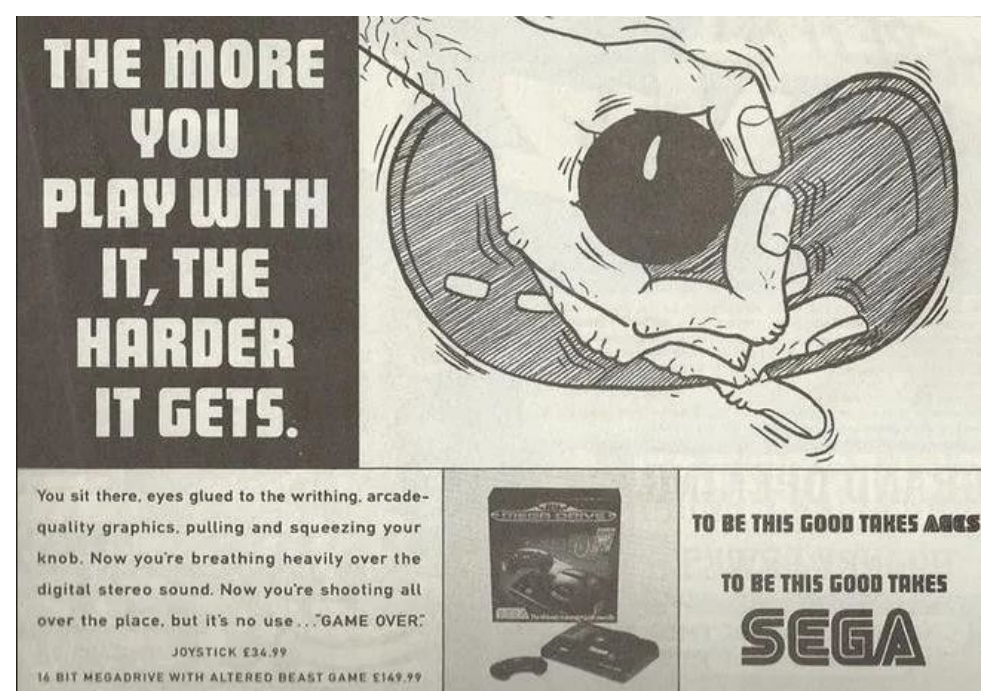

Figure 1.5. Sega mega drive advertisement mapping self-masturbatory phallic play and death to the joystick

Yet entering text into Animal Forest requires that players to navigate both phallic and clitoral analogues by pairing rhythmic button presses with rotating and flicking the joystick, a feeling of writing that is disruptive to historic narratives of writing as a strict analogue for cisgendered male sexual activity. As Phillips concludes, such observations are merely disruptive as they still perpetuate in a problematic gendering of gameplay and game hardware; however, given the largely heteronormative cisgendered rhetorics circulated about players, hardware, and writing, the feeling generated by Animal Forest's writing system presents an important rejection of these analogues. 
From the perspective of media speleology that I have tried to adopt in each of my readings here, Animal Forest's dial input system presents an alternative history of technological feeling, and its gendering in which the upgrade path and the player identities that it invokes are not entirely settled. By troubling linear histories of digital technology, sexuality, and gender via its visual and affective registers, Animal Forest emerges with new technologies that present unimagined (but ever- present) horizons for these very technologies and the implied identities of their players. Yet Animal Forest's dial input system is just one of several different writing systems that appears in the numerous sequels and spin-offs over the series' two decades worth of titles. Future research might explore these other writing systems and their representations to produce a more complete picture of the meaning of writing within the entire series.

\section{Conclusion: Writing Writing Through Video Games}

Writing within video games has already received a tremendous amount of attention dating back to the late 1980s from scholars working in rhetoric and composition and writing studies. We might trace this history back even further if we expand our definition of games to include non- digital forms such as surrealist word and writing games or even Plato's early writings on the relationship between games and writing. Yet, for video games, the question of writing has largely been explored through what Benjamin Miller (2013), in "Metaphor, Writer's Block, and The Legend of Zelda," describes as the logic of metonymy in game studies, "Typically, that is, scholars have investigated the potential for in-game reading, writing, and communication...to inform out-of-game reading, writing, and communication" (Miller, 2013, p. 99). In other words, many scholars have been interested in answering how games have the potential to teach writing or integrate into writing classrooms. While my work here is deeply indebted to these readings and could not exist without them, I offer these feelingbased theories of writing in the Animal Crossing series to encourage a move away from metonymic readings to consider how we might arrive at broader theories and cultural meanings of writing from how writing is sensed and practiced within video games.

Animal Crossing is a particularly interesting series to begin with because it presents a space in which in-game writing cannot be regarded as a closed system. While writing in video games might be dismissed as "less than" the writing performed outside of video games, the deep bonds it creates and that linger long after players close their games suggests that these supposedly closed contexts are anything but separate from the material world. Moreover, Animal Crossing, from the perspective of its writing and writing technologies, invites us to explore ourselves and where we might comfortably cross with computers. We are given a variety of means (including trade, interior design, urban planning, etc.) to make connections and forge bonds with players and NPCs alike, but the writing surface invites a play of feeling along which we can touch (and find ourselves being touched) by a video game in ways that are all too human. While much has been written on Animal Crossing as a space for players to explore their emotions and attachments, perhaps we might inquire into the attachments that our NPC villagers forged with us and take with them as we leave them behind. After all, villagers frequently move from their hometowns into the towns of other players, taking with them items and culture (in the form of catchphrases, references, and other content specific to their 
hometowns). What might these villagers, who keep traveling long after we have turned off Animal Crossing for the final time, hold onto and keep alive of our former friendships and bonds? How long do they travel and repeat "I remember Dangerchunk's favorite snack" across an endless network of interconnected villages.

As we can see just from this overview of writing in Animal Crossing, investigating the ideologies entangled within writing systems matters, as more and more video games lean into writing technology as narrative mechanisms and mechanical metaphors that express important ideas about identity, discourse, feeling, and many other critical issues. Animal Crossing isn't alone in in this practice. The Resident Evil series' typewriters, for example, famously provide a diegetic means to save the game and re-write death that is grounded within and expressive of the series' gothic horror trappings. Dark Souls soapstone messages, similarly, re-enforce the spatial, temporal, and bodily discontinuities at the core of the dark sign, yet they also provide a player- produced means of tutorializing and pacing gameplay encounters. Such protrusions could potentially be read as moments of diegetic recapture where "a sort of crisis in representation...is turned back into the gameworld, so as to seem to be another of its (arbitrary but consistent) rules" (Harpold, 2007); however, as Gitelman notes, "inventing new ways to write or new kinds of writing presupposes a model of what writing and reading are and can be...embodiments of the way people wrote, read, and interacted over the perceived characteristics of writing" (Gitelman, 2000, p. 4). What examining such technologies can offer us, then, are theories and ideas about the feelings associated with writing and reading, many of which have to do with ideas of representation, selfhood, communication, relationships, and more. In this article, I have attempted to begin this work by exploring possible ways of reading and understanding the senses and practice of writing within Animal Crossing. Although this study is limited in scope to the various ways players write across the various entries within the series, through it we can begin to understand how players and game designers are sensing themselves and the history (and future) of writing. 
18 Loading... The Journal of the Canadian Game Studies Association

Vol 13(22): 39-58

http://loading.gamestudies.ca

\section{References}

Anable, A. (2018). Playing with Feelings: Video Games and Affect. Minneapolis, MN: The Minnesota Press.

Bogost, I. (2008). The Rhetoric of Video Games. In K. Salen (Ed.), The Ecology of Games: Connecting Youth, Games, and Learning (pp. 117-140). Cambridge, MA: The MIT Press.

Brathwaite, B. (2013). Sex in Video Games. CreateSpace Independent Publishing

Platform. Cuyler. (2018, July 8). Animal Crossing ACE “Letter2Item” Mod Showcase

[Video file].

Retrieved from https://www.youtube.com/watch?v=BdxN7gP6WIc

erinhasguts. (2014). What kinds of things do you write in your letters to villagers? Message posted to https://www.reddit.com/r/AnimalCrossing/comments/1x2gls/what_kind_of_things_do y ou_write_in_your_letters/

Evermore-Apples. (2014). What kinds of things do you write in your letters to villagers?

Message posted to

https://www.reddit.com/r/AnimalCrossing/comments/1x2gls/what_kind_of_things_do _y ou_write_in_your_letters/

Flores, N. (2019). Why do Animal Crossing's Villagers Leave Such an Impact? Retrieved from https://www.fanbyte.com/features/why-do-animal-crossings-villagers-leavesuch-an- impact/

Flusser, V. (2011). Does Writing Have a Future? Minneapolis, MN: The Minnesota

Press. Flynn-Jones, E. (2014). Game Cutification: A Violent History of Gender, Play and Cute

Aesthetics. Institute for Research on Learning Technologies Research Seminar. Talk presented at 2014 IRLT Research Seminar, Toronto, Ontario.

Gitelman, L. (2000). Scripts, Grooves, and Writing Machines: Representing Technology the Edison Era. Palo Alto, CA: Stanford University Press. 
19 Loading... The Journal of the Canadian Game Studies Association Vol 13(22): 39-58

http://loading.gamestudies.ca

Haas, C. (1995). Writing Technology: Studies on the Materiality of Literacy. Mahwah, NJ: Routledge.

Harpold, T. (2007). Screw the Grue: Mediality, Metalepsis, Recapture. Game Studies, 7(1), n.p. Retrieved from http://gamestudies.org/0701/articles/harpold

Keogh, B. (2018). A Play of Bodies: How We Perceive Videogames. Cambridge, MA: The MIT Press.

King, K. R. (1995). Of Needles and Pens and Women's Work. Tulsa Studies in Women's Literature, 14(1), 77-93. Retrieved from https://www.jstor.org/stable/464249?seq=1

Massumi, B. (2002). Parables for the Virtual: Movement, Affect, Sensation. Durham, NC: Duke University Press.

Miller, B. (2013). Metaphor, Writer's Block, and The Legend of Zelda. In R. Colby, M. Johnson, and R. Colby (Eds.), Rhetoric/Composition/Play Through Videogames (pp. 99-112). New York, NY: Palgrave Macmillan.

Mukherjee, S. (2015). Videogames and Storytelling: Reading Games and Playing Books. New York, NY: Palgrave Macmillan.

Murphy, J. and Zagal J. (2011). Video Games and the Ethics of Care. International Journal of Gaming and Computer-Mediated Simulation, 3(3), 69-81. Retrieved from https://doi.org/10.4018/jgcms.2011070105

Newton, J. (2011). Feature: Celebrating 10 Years of Animal Crossing. NintendoLife. Retrieved from

http://www.nintendolife.com/news/2011/12/feature_celebrating_10_years_of_animal_cr o ssing

NintenDaan. (2013, June 11). [Animal Crossing: New Leaf] Sending letters to villagers [Video file]. Retrieved from https://www.youtube.com/watch?v=tkIRA-yDmEE

Nintendo EAD. (2002). Animal Crossing. Console Videogame. Kyoto, Japan.

Nintendo. Nintendo EAD. (2008). Animal Crossing: City Folk. Console Videogame.

Kyoto, Japan.

Nintendo.

Nintendo EAD. (2020). Animal Crossing: New Horizons. Console Videogame. Kyoto, Japan. Nintendo.

Nintendo EAD. (2012). Animal Crossing: New Leaf. Console Videogame. Kyoto, Japan. 
20 Loading... The Journal of the Canadian Game Studies Association

Vol 13(22): 39-58

http://loading.gamestudies.ca

Nintendo.

Nintendo EAD. (2005). Animal Crossing: Wild World. Console Videogame. Kyoto, Japan. Nintendo.

Nintendo EAD. (2001). Animal Forest. Console Videogame. Kyoto, Japan. Nintendo.

Nommeh. (2014). What kinds of things do you write in your letters to villagers? Message posted to https://www.reddit.com/r/AnimalCrossing/comments/1x2gls/what_kind_of_things_do y ou write in your letters/

Nooney, L. (2013). A Pedestal, A Table, A Love Letter: Archaeologies of Gender in Videogame History. Game Studies, 13(2), n.p. Retrieved from http:/gamestudies.org/1302/articles/nooney

Phillips, A. (2013). Welcome to My Fantasy Zone: Bayonetta and Queer Femme Disturbance. In

A. Shaw and B. Ruberg (Eds.), Queer Game Studies (pp. 109-124). Minneapolis, MN: The Minnesota Press.

Radulovic, P. (2018). The Animal Crossing Letter System, Explained. Retrieved from https://www.polygon.com/2018/8/7/17660344/animal-crossing-letter-systemgame- design-explained

Shouse, E. (2008). Feeling, Emotion, Affect. M/C Journal, 8(6). Retrieved from http://journal.media-culture.org.au/0512/03-shouse.php

Sudnow, D. (1979). Pilgrim in the Microworld. New York, NY: Grand Central

Publishing. Swink, S. (2008). Game Feel. Burlington, MA: Morgan Kaufmann

Publishers.

thevdude. (2014). What kinds of things do you write in your letters to villagers? Message posted to https://www.reddit.com/r/AnimalCrossing/comments/1x2gls/what_kind_of_things_do _y ou_write_in_your_letters/

Wardrip-Fruin. N. (2019). Gravity in Computer Space. ROMchip: A Journal of Game Histories, 1(2), n.p. Retrieved from https://romchip.org/index.php/romchipjournal/article/view/91\#fn-4468c7f2763ce0989511be6382c16707 